\title{
Sertoli cell differentiation in rhesus monkey (Macaca mulatta) is an early event in puberty and precedes attainment of the adult complement of undifferentiated spermatogonia
}

\author{
D R Simorangkir ${ }^{1,+}$, S Ramaswamy ${ }^{1}$, G R Marshall ${ }^{3}$, R Roslund ${ }^{1}$ and T M Plant ${ }^{1,2}$ \\ ${ }^{1}$ Department of Obstetrics, Gynecology and Reproductive Sciences, University of Pittsburgh School of Medicine, \\ Pittsburgh, Pennsylvania 15213, USA, ${ }^{2}$ Magee-Womens Research Institute, University of Pittsburgh, 204 Craft \\ Avenue, Room B311, Pittsburgh, Pennsylvania 15213, USA and ${ }^{3}$ Department of Natural Sciences, Chatham \\ University, Pittsburgh, Pennsylvania 15232, USA
}

Correspondence should be addressed to T M Plant at Magee-Womens Research Institute, University of Pittsburgh; Email: planttm@mwri.magee.edu

${ }^{\dagger}$ D R Simorangkir is now at St. Matthew's University School of Medicine, Grand Cayman, BWI

\begin{abstract}
In primates, the time course of Sertoli cell proliferation and differentiation during puberty and its relationship with the expansion of undifferentiated type A spermatogonia that occurs at this critical stage of development are poorly defined. Mid and late juvenile and early and late pubertal male rhesus monkeys were studied. Testes were immersion fixed, embedded in paraffin, and sectioned at $5 \mu \mathrm{m}$. Sertoli cell number per testis, S-phase labeling (BrdU), and growth fraction (Ki67 labeling) were determined and correlated with corresponding parameters for undifferentiated type A spermatogonia (A dark and A pale). Dual fluorescence labeling was used in addition to histochemistry to monitor spermatogonial differentiation during the peripubertal period using GFR $\alpha-1$ and cKIT as markers. While the adult complement of Sertoli cells/testis was attained in early pubertal monkeys after only a few weeks of exposure to the elevated gonadotropin secretion characteristic of this developmental stage, the number of undifferentiated type A spermatogonia several months later in mid pubertal monkeys was only $50 \%$ of that in adult testes. Both A dark and A pale spermatogonia exhibited high S-phase BrdU labeling at all stages of juvenile and pubertal development. Spermatogonial differentiation, as reflected histochemically and by relative changes in GFR $\alpha-1$ and cKIT expression, was not observed until after the initiation of puberty. In the rhesus monkey and maybe in other higher primates including human, the pubertal proliferation of undifferentiated spermatogonia is insidious and proceeds in the wake of a surge in Sertoli cell proliferation following termination of the juvenile stage of development.
\end{abstract}

Reproduction (2012) 143 513-522

\section{Introduction}

The number of Sertoli cells within the adult testis is considered to be the major determinant of spermatogonial stem cell niches and therefore of spermatogenic ceiling (Sharpe 1994, Griswold 1995, Sharpe et al. 2003). While the control of Sertoli cell proliferation and differentiation has been extensively studied in rodents (Sharpe 1994, Griswold 1995, 1998), this aspect of testicular development has only been scantly investigated in higher primates (Nistal et al. 1982, Cortes et al. 1987, Sharpe et al. 2003, Plant et al. 2005). In monkey and human, the postnatal pattern of Sertoli cell proliferation may be divided into three major developmental phases (Sharpe et al. 2003, Plant et al. 2005). The first is seen during infancy when transiently elevated gonadotropin secretion results in a relatively high rate of
Sertoli cell proliferation (Simorangkir et al. 2003). The second encompasses the remainder of the prepubertal phase of development, when Sertoli cell proliferation continues, albeit at a reduced rate (Marshall \& Plant 1996, Simorangkir et al. 2003), as a result of the relative hypogonadotropic state that characterizes this stage of primate development (Plant \& Witchel 2006). The third and final stage of Sertoli cell proliferation is again robust and occurs during puberty (Marshall \& Plant 1996, Sharpe et al. 2003, Plant et al. 2005) in association with the re-augmentation of $\mathrm{LH}$ and $\mathrm{FSH}$ secretion that is triggered at this phase of development (Plant \& Witchel 2006). During puberty, Sertoli cell differentiation is completed and the adult complement of this somatic cell type of the testis is established.

The spermatogonial stem cell in primates is considered to reside within the population of 
undifferentiated type A spermatogonia that, on the basis of nuclear staining, may be separated into two distinct populations, dark type $A(\mathrm{Ad})$ and pale type A (Ap; Clermont 1972, Plant 2010). As in the case of the Sertoli cell, the adult complement of type A spermatogonia in the primate testis is obtained as a result of a protracted phase of proliferation that spans the infantile, juvenile, and pubertal phase of postnatal development (Plant et al. 2005, Simorangkir et al. 2005). The proliferation of undifferentiated type A spermatogonia, however, appears less dependent on gonadotropin stimulation than that of Sertoli cells, as reflected by relatively high S-phase labeling during juvenile development when LH and FSH secretion are low (Simorangkir et al. 2005).

The purpose of this study was to examine the time course of Sertoli cell proliferation and differentiation during puberty in the rhesus monkey and to determine whether the pubertal expansion of undifferentiated type A spermatogonia occurs concomitantly with the increase in Sertoli cell number or follows in the wake of Sertoli cell proliferation.

\section{Results}

\section{Testis weight and gross morphology}

Mean combined testicular weights at each of the four stages of development are shown in Table 1, together with values for seminiferous cord/tubule diameter. Testis from mid juvenile and late juvenile monkeys comprised seminiferous cords surrounded by connective tissue and grouped into several lobules (not shown). In two of the early pubertal animals rudimentary lumen were observed on occasion, and by the mid pubertal stage of development, mature lumen was observed in many of the seminiferous tubules (Fig. 1). In late juvenile animals, the seminiferous cords contained numerous Sertoli cells with spherical or ovoid nuclei and $\mathrm{Ad}$ and $\mathrm{Ap}$ spermatogonia (Fig. 2). Some Sertoli cell nuclei in the early pubertal testes were pleomorphic, and in the mid pubertal group, these somatic cells were fully mature (Fig. 2). As described previously (Simorangkir et al. 2005), Ad appeared as small cells with a spherical and darkly stained (hematoxylin) nucleus containing dense and homogeneous chromatin, while Ap spermatogonia were larger cells with a lightly stained nucleus and coarse granular chromatin (Fig. 2). The morphology of undifferentiated spermatogonia, as assessed by histochemistry, was indistinguishable in testis from juvenile and pubertal animals.

Occasional differentiating type B1 spermatogonia were observed in testes from two of the three late juveniles. Not surprisingly, the seminiferous epithelium at later stages of development comprised more mature germ cells. All early pubertal testes had germ cells as mature as primary spermatocytes, and one animal in this group had a few round spermatids in about $10 \%$ of the cross sections evaluated. Mid pubertal testes had germ cells as mature as step 14 spermatids, and $\sim 95 \%$ of the cross sections at this stage of development had identifiable stages of the cycle of the seminiferous epithelium.

\section{Sertoli cell number and labeling indices}

The mean number of Sertoli cells per testis in the early pubertal group was $1802 \pm 221 \times 10^{6}$, and this was nearly fourfold greater and significantly different from that of the late juvenile group (Fig. 3). However, there was no further increase in Sertoli cell number between the early pubertal and the mid pubertal stages of development. While BrdU-labeled Sertoli cells were found in testis from late juveniles, S-phase-labeled Sertoli cells were not found in the two pubertal groups (Figs 3 and 4). Ki67 labeling of Sertoli cells was observed in testes of late juvenile monkeys (Fig. 3), minimal in testes from early pubertal animals and absent in the mid pubertal group (Fig. 3). Both BrdU and Ki67 labeling of Sertoli cells was significantly greater in the late juvenile group than in the two more mature groups (Fig. 3). In the mid juvenile group, the mean Ki67-labeling index was $1.2 \pm 0.1 \%$.

Interestingly, the mean number of Sertoli cells per tubular cross section in the early pubertal group (25.4 \pm 1.7 ) was significantly greater than that of either the late juvenile $(14.1 \pm 2.1)$ or mid pubertal group (18.8 \pm 1.9$)$. This was not the case for total A spermatogonia (late juvenile, $0.9 \pm 0.4$; early pubertal, $1.1 \pm 0.1$; and mid pubertal, $1.2 \pm 0.3)$.

Table 1 Age, combined testes weight, seminiferous cord/tubule diameter, and body weight of mid juvenile, late juvenile, early pubertal, and mid pubertal monkeys (mean \pm s.D.).

\begin{tabular}{lccc}
\hline Group & Age at castration (months) & Combined testis weight $(\mathrm{g})$ & $\begin{array}{c}\text { Seminiferous cord/tubule } \\
\text { diameter }(\mu \mathrm{m})\end{array}$ \\
\hline Mid juvenile $(n=3)$ & $13.8 \pm 0.43$ & $0.90^{\mathrm{a}}$ & $\mathrm{Nody}$ weight at castration \\
$(\mathrm{kg})$
\end{tabular}

\footnotetext{
NA, not available.

a Based on the weight of one testis from two animals.
} 

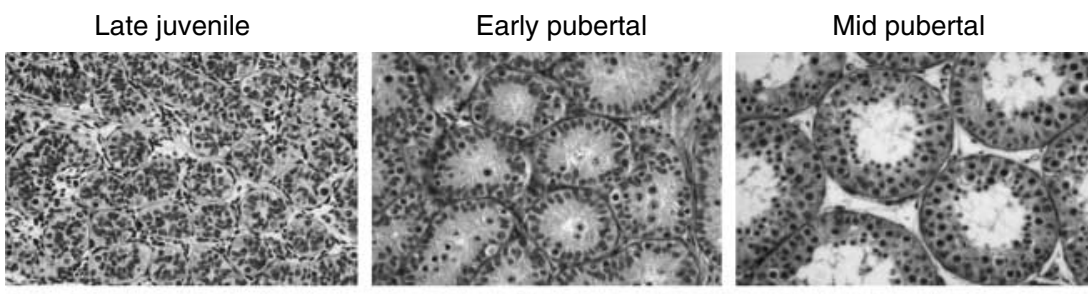

Figure 1 Photomicrographs obtained from PAS-hematoxylin-stained sections from testes of late juvenile (left-hand panels), early pubertal (center panels), and mid pubertal (right-hand panels) monkeys. Top and bottom sections represent the least and most mature testis, respectively, in each of the three groups. Note, in the mid pubertal testis, many tubules are characterized by the presence of lumen and identifiable stages of the seminiferous epithelial cycle. Scale bar, $50 \mu \mathrm{m}$.

\section{Ad and Ap number and labeling indices}

The number of $\mathrm{Ad}$ and Ap spermatogonia per testis in the late juveniles was $20.5 \pm 24.4 \times 10^{6}$ and $23.9 \pm 18.1$ $\times 10^{6}$, respectively, and by mid puberty, the number of these undifferentiated spermatogonia had increased approximately two- to three-fold (Fig. 5). The increase in the Ap spermatogonia number during this period of pubertal development was statistically significant. The amplification in the number of Ad and Ap spermatogonia during this phase of pubertal development was associated with robust BrdU labeling (3-14\%; Fig. 5). Examples of BrdU-labeled Ad spermatogonia in testis from late juvenile, early pubertal, and mid pubertal monkeys are shown in Fig. 4.

\section{CKIT expression in spermatogonia}

cKIT-expressing germ cells were rarely observed in testes from mid juvenile and late juvenile animals, accounting on an average for only one in $\sim 35$ spermatogonia expressing GFR $\alpha-1$ and/or CKIT (Fig. 6). With the initiation of puberty, however, the relative proportion of cKIT-positive spermatogonia increased dramatically and in the testes of mid pubertal animals, two of every three cells expressing one or both of these markers were cKIT positive (Fig. 6).

\section{Discussion}

A major finding of this study on the rhesus monkey was that the pubertal proliferation and terminal differentiation of Sertoli cells is an early, and relatively rapidly completed, event during this critical stage of postnatal development in primates. The testis of the adult rhesus monkey typically contains 1500-2000 million Sertoli cells (Marshall \& Plant 1996), and in this study, this number was observed in the early pubertal group. Moreover, in two of the three monkeys in this developmental group, the juvenile testes had been exposed to only 4-6 weeks of elevated gonadotropin secretion, as reflected by the time course of circulating testosterone concentrations. The attainment of an adult complement of Sertoli cells in the early pubertal monkeys was consistent with the mature morphology and absence of S-phase and Ki67 labeling of these somatic cells at this stage of development. The appearance of spermatocytes and rudimentary lumen in testis from early pubertal monkeys is indicative of establishment of the blood-testis barrier (Gondos \& Berndtson 1993) and, therefore, further supports an early cessation of Sertoli cell proliferation at puberty in this species. The rapid attainment of an adult number of Sertoli cells during spontaneous pubertal development in the monkey is in line with results reported for this
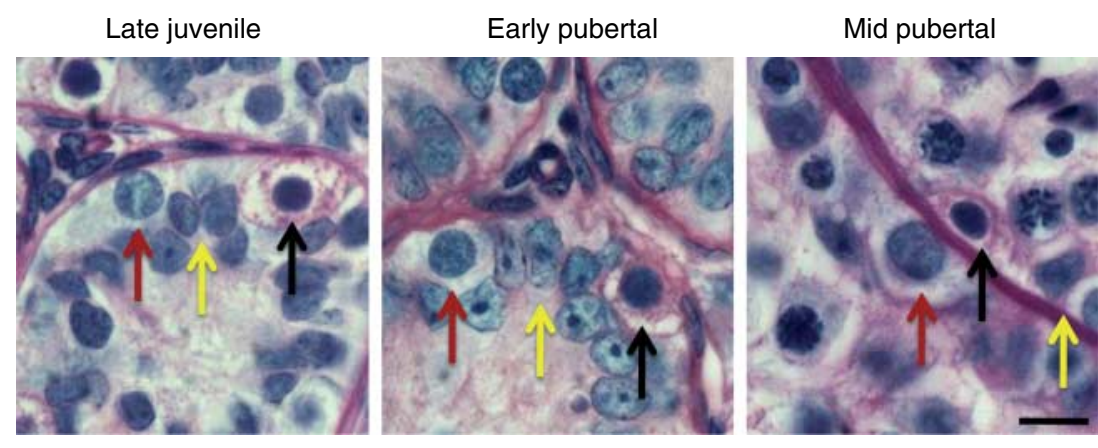

Figure 2 Photomicrographs obtained from PAS-hematoxylin-stained sections from testes of late juvenile (left-hand panel), early pubertal (center panel), and mid pubertal (right-hand panel) monkeys showing morphology of Sertoli cell nuclei (yellow arrow), Ap spermatogonia (red arrow), and Ad spermatogonia (black arrow) at each of the three developmental stages.

Scale bar, $10 \mu \mathrm{m}$. 


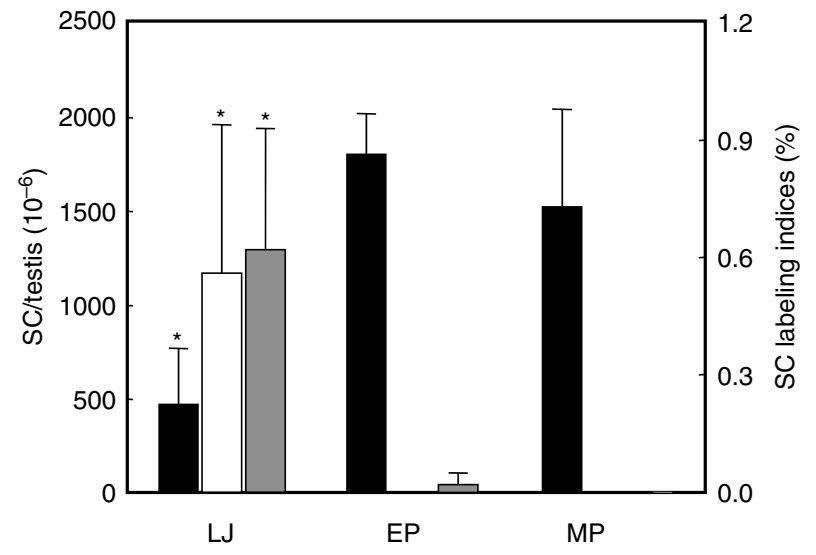

Figure 3 Mean number ( \pm s.D.) of Sertoli cells/testis (black histogram), BrdU Sertoli cell (SC)-labeling index (white histogram), and Ki67 Sertoli cell-labeling index (gray histogram) for late juvenile (LJ), early pubertal (EP), and mid pubertal (MP) monkeys. $n=3$ for each developmental stage. *Significantly different from early and mid pubertal groups.

species when testicular puberty was induced prematurely by stimulation with either exogenous or endogenous gonadotropin, the latter generated by a pulsatile GnRH infusion. Treatment of juvenile monkeys, $\sim 18$ months of age, with recombinant human gonadotropin for 11 days resulted in a $50 \%$ increase in Sertoli cell number (Ramaswamy et al. 2000), and initiation of precocious puberty in similar aged animals with 10 weeks of pulsatile GnRH treatment produced a fivefold increase in Sertoli cell number (Marshall \& Plant 1996). Together, these findings provide support for the view that the proliferation and differentiation of the Sertoli cell during spontaneous puberty is driven by the increase in gonadotropin secretion at this stage of development (Plant \& Witchel 2006), as reflected in this study by the time course of circulating testosterone. The relative role and temporal actions of $\mathrm{LH}$ and $\mathrm{FSH}$ in this regard, however, remains to be fully documented for higher primates.

BrdU labeling of Sertoli cells in the late juvenile animals $(0.55 \%)$ was somewhat greater than that reported by us for younger juveniles $(0.25 \%$; Simorangkir et al. 2003), comparable in age to those comprising the mid juvenile group of this study. This difference may indicate that the onset of puberty had already been initiated in the late juvenile animals, although the endocrine index (weekly circulating testosterone) was insufficiently sensitive to reflect the developmental event. This view is supported by the finding that in two of the late juvenile monkeys the very occasional differentiating B1 spermatogonia was observed, and in one of these two animals, numerous Leydig cells were found (Verhagen \& Plant, unpublished observations, 2010). The finding that the foregoing mitotic index for Sertoli cells was similar to the Ki67-labeling index suggests that the cell cycle of the proliferating population of Sertoli cells during juvenile development is of short duration and that only a small proportion of this cell type is likely in the growth fraction at any one time.

In contrast to the dynamics of Sertoli cell division at puberty, the proliferation of undifferentiated spermatogonia, both $\mathrm{Ad}$ and $\mathrm{Ap}$, was relatively insidious throughout this phase of development, and as a result, the number of these germ cells reported for the adult monkey $\left(250 \times 10^{6}\right.$ for Ad and for Ap) by our laboratory (Marshall \& Plant 1996) had not been reached by the time the mid juvenile group were castrated. The protracted proliferation of undifferentiated spermatogonia through puberty was associated with an S-phaselabeling index, in both $\mathrm{Ad}$ and $\mathrm{Ap}$, that was greatest in the early pubertal animals. It is tempting to speculate that the high S-phase labeling in undifferentiated spermatogonia in early pubertal monkeys is a consequence of an increase in spermatogonial niches, resulting from the pubertal surge in Sertoli cell proliferation and reflected by the significant increase in the number of Sertoli cells per cross section at this stage of development. The failure to observe an early pubertal peak in Sertoli cell number per cross section in boys (Paniagua \& Nistal 1984) probably reflects the fact that this metric was related to age rather than stages of sexual maturation. The S-phase-labeling index for Ap spermatogonia of the late juvenile group $(\sim 3 \%)$ was similar to that reported for this type of undifferentiated spermatogonia in mid juvenile animals (Simorangkir et al. 2005). In the case of
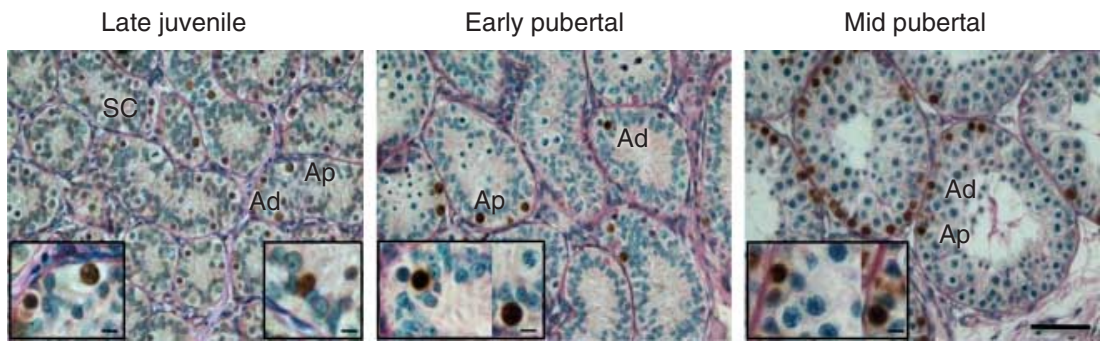

Figure 4 Photomicrographs of representative testis section from late juvenile (left panel), early pubertal (center panel), and mid pubertal (right panel), in which S-phase-labeled cells have been identified immunohistochemically (brown) and counterstained with PAS-hematoxylin. BrdU-labeled Sertoli cells (SC) were observed in only testis from late juvenile, while Ad and Ap spermatogonia were observed at all three stages of development. Left inset in each panel shows BrdU-labeled Ad (left) and Ap (right) spermatogonia at a higher magnification. Right inset in late juvenile shows BrdU-labeled SC. Scale bar, 50 and $5 \mu \mathrm{m}$ (insets). 

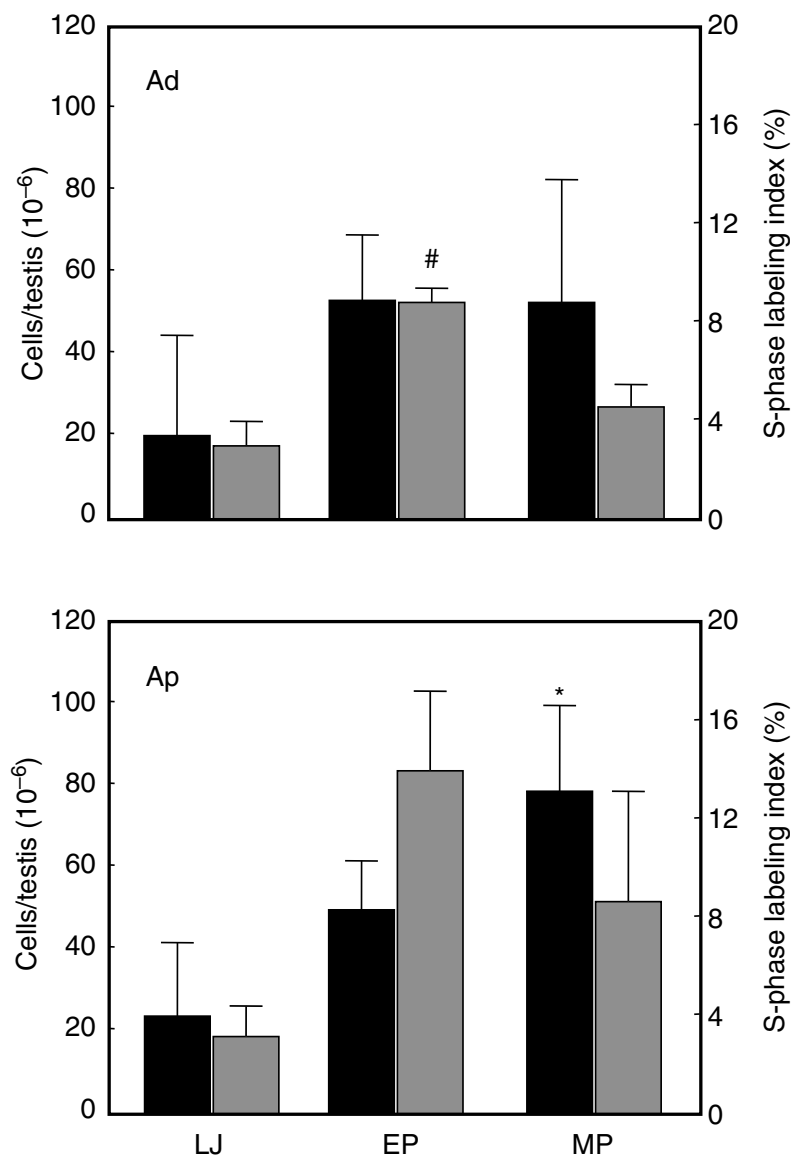

Figure 5 Mean number ( \pm s.D.) of Ad spermatogonia/testis (top panel, black histogram) and Ap spermatogonia/testis (bottom panel, black histogram), together with their BrdU-labeling indices (gray histogram) for the late juvenile (LJ), early pubertal (EP), and mid pubertal (MP) groups. "Significantly different from LJ and MP; * significantly different from LJ. $n=3$ for each group.

Ad spermatogonia, S-phase labeling observed for the late juveniles in this study was noticeably less than that reported earlier for mid juveniles (Simorangkir et al. 2005), and we are unable to offer an explanation for this. The full time course of the pubertal increase in undifferentiated spermatogonial number remains to be determined because a late pubertal group was not included in this study.

Considerable controversy surrounds the issue of the mitotic behavior of Ad dark spermatogonia (Ehmcke \& Schlatt 2006, Hermann et al. 2010, Plant 2010). In the adult, classic studies on the monkey testis conducted in the 1960s led Clermont (1972) to propose that these cells very rarely divide and he therefore tentatively termed them reserve stem cells. This view, in general, has prevailed (de Rooij \& Russell 2000, Simorangkir et al. 2009, Plant 2010), although recent studies of molecular markers expressed by $\mathrm{Ad}$ and $\mathrm{Ap}$ in the adult monkey (Hermann et al. 2009) testis have led some investigators to begin to question the classic view of Clermont (Hermann et al. 2010). In the prepubertal testis, however, extensive S-phase BrdU labeling of Ad spermatogonia was reported earlier by this laboratory (Simorangkir et al. 2005): a finding confirmed in this study. Thus, it seems reasonable to conclude that robust proliferation of $\mathrm{Ad}$ spermatogonia in the prepubertal testis accounts for the $\sim 500$-fold amplification in the population of $\mathrm{Ad}$ spermatogonia in the monkey testis that occurs from birth until attainment of adulthood (Marshall \& Plant 1996). The signals in the adult testis that are responsible for taking Ad spermatogonia out of the cell cycle remain to be established.

The discordancy in the time course of Sertoli cell proliferation vs that of undifferentiated spermatogonia likely reflects the relatively greater dependency of Sertoli cell proliferation on gonadotropin secretion (Marshall \& Plant 1996, Plant et al. 2005). Accordingly, with the reaugmentation of robust $\mathrm{LH}$ and $\mathrm{FSH}$ release at the initiation of puberty, a surge of Sertoli cell proliferation is stimulated, but proliferation of undifferentiated spermatogonia being relatively gonadotropin independent (Marshall et al. 2005, Simorangkir et al. 2005) continues at a rate similar to that for the juvenile.

The absence of histochemically identified differentiating B spermatogonia in testes from the mid juvenile group is consistent with our earlier observations (Marshall \& Plant 1996, Simorangkir et al. 2005) and with the present finding of a very low ratio of $\mathrm{CKIT}^{+}$to GFR $\alpha-1^{+}$germ cells in testes at this stage of development. Although, the occasional B spermatogonia was observed in two of the three late juvenile animals in this study, the ratio of these molecular markers of spermatogonial differentiation at this stage of development was similar to that in the mid juvenile group. In any event, the present findings illustrate the imprecision that can arise when using circulating testosterone and testicular volume as markers of the initiation of the onset of puberty in the male monkeys. Before leaving the question of spermatogonial differentiation in the prepubertal primate testis, it should be noted that, in contrast to the monkey, significant numbers of differentiating spermatogonia have been described in boys at ages equivalent to our mid to late juvenile monkeys (Paniagua \& Nistal 1984). It is likely that this difference reflects the relative gonadotropin drive to the prepubertal testis in juvenile boys and male monkeys.

In summary, the present investigation has demonstrated that, in the rhesus monkey, the pubertal proliferation of undifferentiated spermatogonia is insidious and proceeds in the wake of a surge in Sertoli cell number following termination of the juvenile stage of development. The entire time course of the postnatal increase in the numbers of Sertoli cells and undifferentiated type A spermatogonia in the monkey testis from birth to adulthood is shown in Fig. 7. The data shown in this figure have been generated by this laboratory over the last 15-20 years (Marshall \& Plant 1996, Simorangkir et al. 2003, 2005; and this study). 

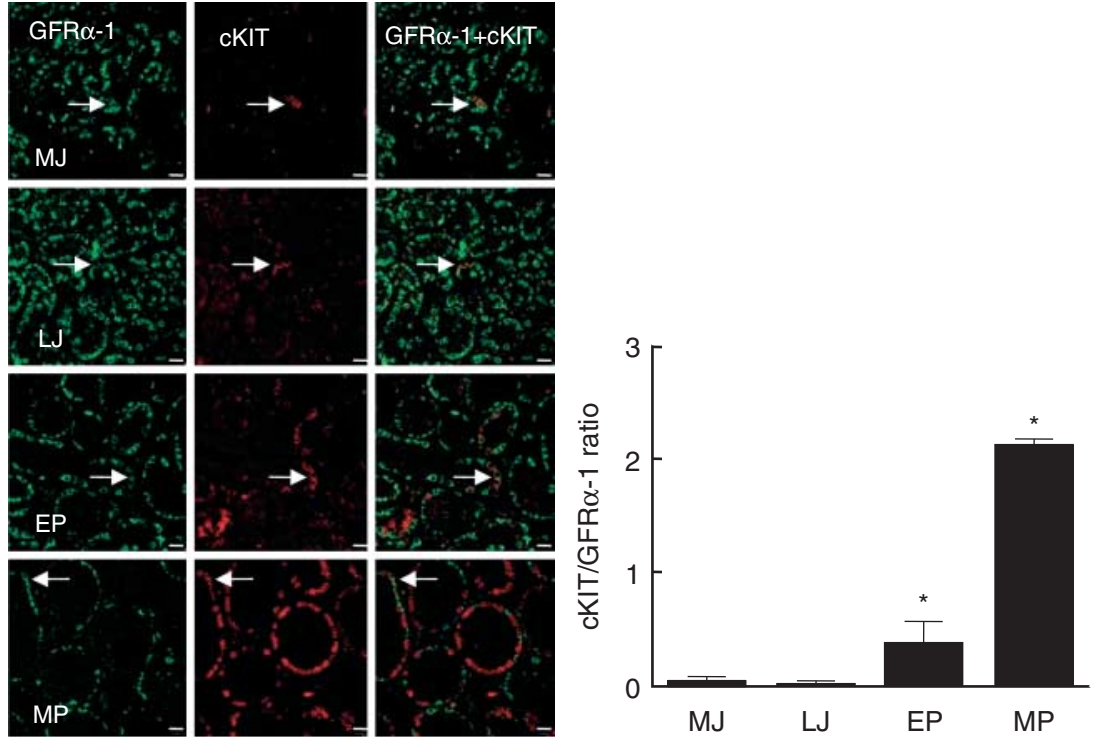

Figure 6 cKIT expression increases markedly in the testis of early and mid pubertal monkeys. Left panel: confocal immunofluorescence projections showing GFR $\alpha$-1 (left-hand panels, green fluorescence, Alexa 488) or CKIT (middle panels, red fluorescence, Cy3) expressing germ cells and their merged images (right-hand panels) in testes of a mid juvenile (MJ), late juvenile, (LJ) early pubertal (EP), and mid pubertal (MP) monkeys. Arrows indicate dual labeled spermatogonia. Scale bar, $20 \mu \mathrm{m}$. Right panel: the ratio of $\mathrm{CKIT}^{+}$to GFR $\alpha-1^{+}$ spermatogonia (mean \pm s.D.) in testes from MJ, LJ, $\mathrm{EP}$, and MP monkeys. *Significantly different from all other groups.

\section{Materials and Methods}

\section{Animals}

Nine male rhesus monkeys (Macaca mulatta), born either in the USA (Indian rhesus) or in China and purchased from Three Springs Scientific (Perkasie, PA, USA), were employed. At the beginning of the experiment, the animals ranged from 28 to 32 months of age. The monkeys were maintained under a controlled photoperiod (lights-on 0700-1900 h) at an ambient temperature of $21^{\circ} \mathrm{C}$. The experiments were conducted in accordance with NIH Guidelines for the Care and Use of Experimental Animals and were approved by the University of Pittsburgh Institutional Animal Committee on Use and Care.

\section{Experimental protocol}

The nine juveniles were randomly assigned to three groups, namely, late juvenile, early pubertal, and mid pubertal. Testicular development in these nine animals was tracked by monitoring testicular volume and location (inguinal vs scrotal) and morning $(\sim 0830 \mathrm{~h})$ and nighttime (Fig. 8; $\sim 1900 \mathrm{~h}$ ) circulating testosterone concentrations on a weekly basis. The initiation of the onset of puberty in the male rhesus monkey may be recognized by an increase in nighttime circulating testosterone concentrations, which, in our laboratory, typically occur at $\sim 36$ months of age (Plant 1985). Animals were classified as early pubertal when combined testicular volume reached $5 \mathrm{ml}$ and maintenance of nighttime testosterone concentration in excess of $1 \mathrm{ng} / \mathrm{ml}$ and for several weeks (Fig. 1, Fig. 8). Mid pubertal animals were classified as such by combined testicular volumes of at least $15 \mathrm{ml}$ and maintenance of nighttime testosterone concentrations in excess of $1 \mathrm{ng} / \mathrm{ml}$ for $>10$ weeks (Fig. 1, Fig. 8). The late juvenile animals were 28-30 months of age with testicular volumes $<5 \mathrm{ml}$ and showing no evidence of increased circulating testosterone concentrations (Fig. 1, Fig. 8).

Late juvenile monkeys were castrated between 33 and 36 months of age, while early pubertal and mid pubertal animals were castrated between 38 and 47, 45 and 51 months of age respectively. An i.v. bolus of BrdU (33 mg/kg body weight as a $2 \%$ solution in PBS; Sigma Chemical Co.) was injected $3 \mathrm{~h}$ before the removal of the testes.

In addition, testes from three additional juvenile monkeys (13-15 months of age) that were castrated for an unrelated study (Ramaswamy et al. 2010) were also employed. Testes from these animals, which were also labeled with BrdU, were fixed in Bouin's or 4\% paraformaldehyde and comprised a mid juvenile group.

The total number of Sertoli cells and Ad and Ap spermatogonia per testis were enumerated for the late juvenile, early pubertal, and mid pubertal groups. S-phase

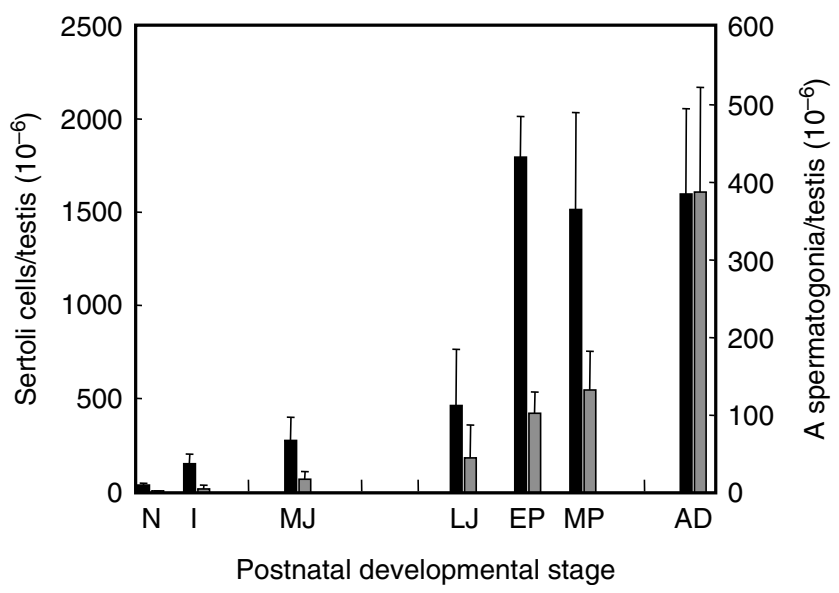

Figure 7 The temporal relationship throughout postnatal development between the attainment of adult complements of Sertoli cell number (closed histograms) and the undifferentiated type A spermatogonia number (gray histograms) in the testis of the rhesus monkey. Equal numbers of Ad and Ap per testis are typically observed throughout postnatal development. $\mathrm{N}$, neonate (1-2 days old); I, infant (4-5 months old); MJ, mid juvenile (38-47 months old), LJ, late juvenile (33-36 months old); EP, early pubertal (45-51 months old), MP, mid pubertal (45-51 months old) and AD, adult ( $>6$ years of age). Data for $N, I, M J$, and AD from Marshall \& Plant (1996) and Simorangkir et al. (2005, 2009). 

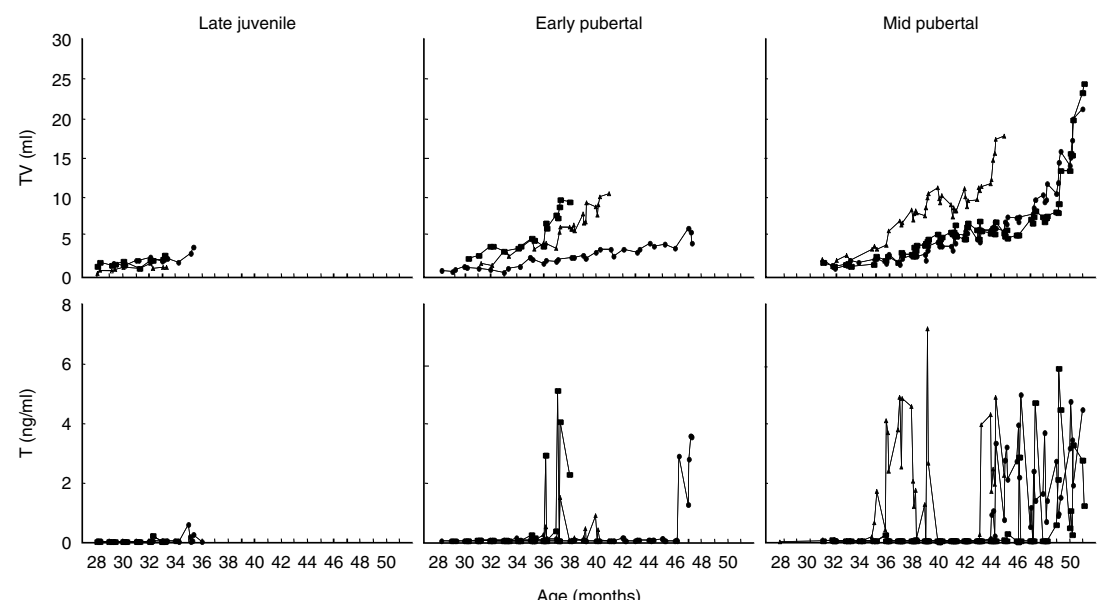

Age (months)

(BrdU)-labeling indices were calculated for Sertoli cells and for Ad and Ap spermatogonia at these three developmental stages.

At all four stages of development, Sertoli cell growth fraction was determined using Ki67 as a marker of proliferating cells (Whitfield et al. 2006). For this purpose, GATA4 was used as a marker of Sertoli cells (LaVoie 2003). Spermatogonial differentiation was assessed using GFR $\alpha-1$ and cKIT as markers of undifferentiated and differentiating spermatogonia (Aponte et al. 2005, Hermann et al. 2009) respectively.

\section{Blood sampling}

Single daily blood samples $(\sim 1 \mathrm{ml})$ were drawn into heparinized syringes once per week at 0830 and $1900 \mathrm{~h}$, after monkeys had been sedated with ketamine hydrochloride (10-20 mg/kg body weight i.m., Ketaject; Phoenix Scientific, Inc., St. Joseph, MO, USA). Plasma was separated and stored at $-20{ }^{\circ} \mathrm{C}$ until required for assays.

\section{Hormonal measurements}

Circulating testosterone concentrations were measured using a RIA (Coat-A-Count, TKTT5; Diagnostic Products Corp., Los Angeles, CA, USA) as described previously (Ramaswamy 2005). The sensitivity of this assay was $0.4 \mathrm{ng} / \mathrm{ml}$, and the intra- and interassay coefficients of variation were $<7.1$ and $<10.2 \%$ respectively.

\section{Testicular volume measurement}

Testis width and length were measured by one of the authors (S Ramaswamy) with a caliper while monkeys were sedated for weekly blood sample collection. The location of testes was noted at this time. Combined testis volume was calculated as described previously (Ramaswamy et al. 2000).

\section{Castration and processing of testicular tissue}

The testes were removed via a midline incision, after sedation with ketamine hydrochloride ( $20 \mathrm{mg} / \mathrm{kg}$ body weight, i.m.) and anesthesia with $1.5-2.5 \%$ isoflurane in oxygen. Following castration, testes were weighed and cut into several fragments for immersion fixation overnight in Bouin's solution or $10 \%$ neutral buffered formalin or $4 \%$ paraformaldehyde and processed for paraffin embedding. Postoperatively, each monkey received antibiotic and analgesic treatments as described previously (Ramaswamy et al. 2010).

\section{Morphometric analysis}

Bouin's fixed testicular tissue was sectioned at $5 \mu \mathrm{m}$ and stained either with hematoxylin only or with periodic acidSchiff (PAS)-hematoxylin (Sigma Chemical Co.). Because of the need to relate the data from this study to those observed earlier for neonate, infant, mid juvenile, and adult stages of postnatal development, the same classical method of cell enumeration that had been employed previously was again selected, rather than switching to the more contemporary optical dissector. In the late juvenile group, Sertoli cell numbers were enumerated by counting the number of Sertoli cell nuclei in seminiferous cords with circular profiles, a method similar to that used by this laboratory to estimate Sertoli cell number in the neonate, infant, and mid juvenile testes (Simorangkir et al. 2003). The nuclei of Sertoli cells in the monkey testis before the onset of puberty are spherical/ovoid, a requirement for quantification (Abercrombie 1946). In the early and mid pubertal groups, Sertoli cell number was estimated by counting their nucleoli, instead of their nuclei, also as described (Simorangkir et al. 2009). Differentiating Sertoli cells possess an irregular shaped nucleus but contain only a single spherical and prominent nucleolus. The volume fraction, absolute volume, diameter, and length of the seminiferous cords/tubules were measured and calculated as described (Marshall \& Plant 1996). The total number of Sertoli cells per testis was then determined by multiplying cell number per cross section (after a correction using Abercrombie's formula; Abercrombie 1946) with the total length of cord or tubule divided by the section thickness $(5 \mu \mathrm{m})$. A total 60-202 circular profiles per animal in each developmental group were examined. Circular profiles were identified across the entire section by moving the microscope stage systematically in order to avoid counting the same profile more than once. This principle was applied for both cell number enumeration and estimation of labeling indices (below). 
Enumeration of Ad and Ap spermatogonia was performed according to Marshall \& Plant (1996). Ad and Ap spermatogonial nuclei were counted from 200 to 229 circular profiles of seminiferous cord cross section per animal. These numbers were also corrected using Abercrombie's formula (Abercrombie 1946). Total number of Ad dark and Ap pale spermatogonia per testis was obtained as described earlier for Sertoli cell number.

Sertoli cell and spermatogonial number were not determined in the testes from mid juvenile monkeys.

\section{Immunohistochemistry}

\section{BrdU labeling}

BrdU incorporated into DNA was immunohistochemically identified using the method described by our laboratory (Simorangkir et al. 2009). The anti-BrdU antibody (mouse IgG MAB; Roche Diagnostic Corp.) was used at a dilution of 1:33 in $50 \mathrm{mM}$ PBS containing $0.05 \%$ Triton and 1\% normal horse serum. After several rinses, sections were incubated at room temperature with biotinylated horse antimouse antiserum (Vector Laboratories, Inc., Burlingame CA, USA, diluted 1:200 in PBS) for $1 \mathrm{~h}$. After rinsing, sections were treated with avidin-HRP complex (Vectastain ABC Elite Kit, Vector Laboratories, Inc.) for $1 \mathrm{~h}$ at room temperature. HRP was then visualized with 3,3-diaminobenzidine (SigmaFast DAB/Cobalt; Sigma Chemical Co.). A dark brown precipitate indicated the presence of BrdU in the cells. Sections were then counterstained using PAS-hematoxylin.

\section{Ki67 and GATA4 dual fluorescent labeling}

Formalin- or $4 \%$ paraformaldehyde-fixed testicular sections ( $5 \mu \mathrm{m}$ thick) were deparaffinized in xylene and rehydrated through a series of decreasing concentrations of ethyl alcohol and washed in PBS (0.1 M, pH 7.2). The sections were then subjected to antigen retrieval for $1 \mathrm{~h}$ at $97.5^{\circ} \mathrm{C}$ in sodium citrate buffer (tri-sodium citrate solution, $\mathrm{pH} 6.0$, with $0.05 \%$ Tween 20), allowed to cool at room temperature for $30 \mathrm{~min}$, and washed in PBST buffer (PBS with $0.1 \%$ Triton X-100 and $1 \%$ Tween-20, $\mathrm{pH} 7.2$ ). This was followed by incubations in blocking buffer (PBS with 5\% normal donkey serum, 3\% BSA and $1 \%$ Triton X-100 (PBST)) for $30 \mathrm{~min}$ and then in a cocktail of primary antibodies composed of goat antimouse GATA4 antibody (sc-1237, 1:400; Santa Cruz Biotechnology, Inc., Santa Cruz, CA, USA) and mouse monoclonal antihuman Ki67 antibody (Clone MIB-1, 1:200; Dako North America, Inc., Carpinteria, CA, USA) for $90 \mathrm{~min}$ at room temperature in a humidified box. Control sections without the primary antibody were incubated with blocking buffer only. Sections were then rinsed in PBST, incubated in a mixture of secondary fluorescent antibodies, namely Cy3-conjugated AffiniPure donkey antigoat IgG (Jackson ImmunoResearch Laboratories, Inc., West Groove, PA, USA), and Alexa Fluor 488 donkey antimouse IgG (Invitrogen Corporation), both at 1:200 dilution in blocking buffer, for $45 \mathrm{~min}$ at room temperature in the dark. Finally, sections were washed in PBST, briefly cleared in xylene, and coverslipped with Fluoromount-G mounting medium (Southern Biotech, Birmingham, AL, USA).

Confocal imaging of dual fluorescence (GATA4 and Ki67)labeled Sertoli cells was performed as described previously (Ramaswamy et al. 2008), using an Olympus FV1000 confocal microscope equipped with a four-laser system with transmitted light, differential interference contrast (DIC), and complete integrated image analysis software system (Olympus America, Inc., Melville, NY, USA). Optical images along the $z$-axis were collected at $1 \mu \mathrm{m}$ intervals. Composite digital images were then converted to TIFF format, imported into Adobe Photoshop (Adobe Photoshop CS3 extended, version 10.0.1; Adobe Systems, Inc.), and color balance was adjusted for presentation (Fig. 9). Selective omission of primary antibodies led to loss of the respective immunohistochemical signal (Supplementary Figure 1, see section on supplementary data given at the end of this article).

\section{GFR $\alpha-1$ and CKIT dual fluorescence labeling}

Formalin- or $4 \%$ paraformaldehyde-fixed testicular sections ( $5 \mu \mathrm{m}$ thick) were processed for GFR $\alpha-1$ and CKIT immunofluorescence labeling essentially as described earlier. The cocktail of primary antibodies was composed of a mouse MAB against recombinant human GFR $\alpha-1$ (1:200; R\&D Systems, Inc., Minneapolis, MN, USA) and a rabbit polyclonal antihuman CKIT antibody (1:400; Dako North America, Inc., Carpinteria, CA, USA). Alexa Fluor 488 donkey antimouse IgG (Invitrogen Corporation) and Cy3-conjugated AffiniPure donkey antirabbit IgG (Jackson ImmunoResearch Laboratories, Inc.), both at 1:200 dilution, were used as the secondary antibodies. Confocal imaging of dual fluorescence of GFR $\alpha-1$
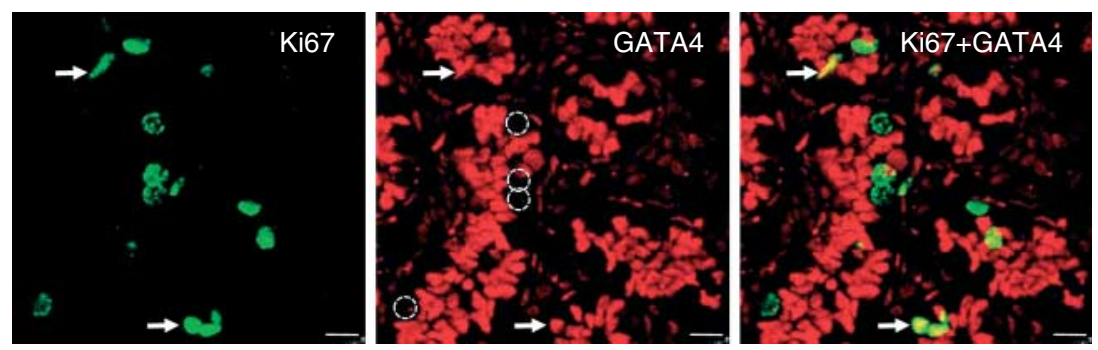

Figure 9 Confocal immunofluorescence projections ( $1 \mu \mathrm{m}$ optical sections) showing co-localization of Ki67 (green fluorescence, Alexa 488 ) and GATA4 (red fluorescence, Cy3) in Sertoli cells from a mid juvenile testis. From left to right, immunopositive Ki67 (left-hand panel), GATA4 (center panel), and their merged image (right-hand panel). White arrows, Ki67-positive Sertoli cells. Broken circles in center panel; site of Ki67-positive spermatogonia. Scale bar, $10 \mu \mathrm{m}$. 
and CKIT was performed as described earlier. Selective omission of primary antibodies led to loss of the respective immunohistochemical signal (Supplementary Figure 1, see section on supplementary data given at the end of this article).

\section{Labeling indices}

\section{S-phase}

This labeling index was determined for individual animals by dividing the number of BrdU-labeled cells by the respective total number of cells determined in circular profiles as described previously (Simorangkir et al. 2003, 2009). As many as 7000 Sertoli cells and 1200 undifferentiated A spermatogonia were evaluated for each monkey.

\section{Sertoli cell growth fraction}

The Sertoli cell growth fraction was estimated for individual animals by dividing the number of Sertoli cells in the cell cycle (Ki67 and GATA4 positive) by the total number of Sertoli cells (GATA4 positive) determined in circular profiles. Approximately, 3500 Sertoli cells per animal were examined.

\section{cKIT-positive spermatogonia}

Approximately, 1000 spermatogonia positive for GFR $\alpha$-1 and/or CKIT and located on the basement membrane were counted in circular cord/tubule profiles for each animal in each of the four groups and the ratio of cKIT/GFR $\alpha-1$ was then calculated.

\section{Statistical analysis}

All numerical data are expressed as mean \pm s.D. For all parameters, the significance of differences between the means across peripubertal development was compared using one-way ANOVA followed by the Newman-Keuls multiple comparison test (Prism 5; GraphPad Software, Inc., La Jolla, CA, USA). As percentages are binominally distributed, the labeling indices were rendered to a normal distribution using arcsine transformation (Zar 1974). Significance was assigned at $P \leq 0.05$.

\section{Supplementary data}

This is linked to the online version of the paper at http://dx.doi. org/10.1530/REP-11-0411.

\section{Declaration of interest}

The authors declare that there is no conflict of interest that could be perceived as prejudicing the impartiality of the research reported.

\section{Funding}

This study was supported by the Eunice Kennedy Shriver National Institute of Child Health and Human Development through cooperative agreement U54 HD 08610 as part of the Specialized Cooperative Centers Program in Reproduction and Infertility Research.

\section{Acknowledgements}

The authors thank the Primate and Assay Core staff (Mr Mike Cicco and Ms Carolyn Phalin) of the Specialized Cooperative Centers Program in Reproduction and Infertility Research at the University of Pittsburgh Medical School for their expert technical assistance. We should also like to acknowledge that Dr Natalia Kostereva suggested the use of GATA4 as a Sertoli cell marker.

\section{References}

Abercrombie M 1946 Estimation of nuclear population from microtome sections. Anatomical Record 94 239-247. (doi:10.1002/ar.1090940210)

Aponte PM, Van Bragt MPA, de Rooij DG \& Van Pelt AMM 2005 Spermatogonial stem cells: characteristics and experimental possibilities. APMIS 113 727-742. (doi:10.1111/j.1600-0463.2005.apm_302.x)

Clermont Y 1972 Kinetic of spermatogenesis in mammals: seminiferous epithelium cycle and spermatogonia renewal. Physiological Reviews 52 198-236.

Cortes D, Muller J \& Skakkebaek NE 1987 Proliferation of Sertoli cells during development of the human testis assessed by stereological methods. International Journal of Andrology 10 589-596. (doi:10.1111/j. 1365-2605.1987.tb00358.x)

Ehmcke J \& Schlatt S 2006 A revised model for spermatogonial expansion in man: lessons from non-human primates. Reproduction 132 673-680. (doi:10.1530/rep.1.01081)

Gondos B \& Berndtson WE 1993 Postnatal and pubertal development. In The Sertoli Cell, pp. 115-154. Eds LD Russell\& MD Griswold. Clearwater: Cache River Press.

Griswold MD 1995 Interactions between germ cells and Sertoli cells in the testis. Biology of Reproduction 52 211-216. (doi:10.1095/biolreprod52. 2.211)

Griswold MD 1998 The central role of Sertoli cells in spermatogenesis. Seminars in Cell \& Developmental Biology 9 411-416. (doi:10.1006/ scdb.1998.0203)

Hermann BP, Sukhwani M, Simorangkir DR, Chu T, Plant TM \& Orwig KE 2009 Molecular dissection of the male germ cell lineage identifies putative spermatogonial stem cells in rhesus macaques. Human Reproduction 7 1704-1716. (doi:10.1093/humrep/dep073)

Hermann BP, Sukhwani M, Hansel MC \& Orwig KE 2010 Spermatogonial stem cells in higher primates: are there differences from those in rodents? Reproduction 139 479-493. (doi:10.1530/REP-09-0255)

LaVoie HA 2003 The role of GATA in mammalian reproduction. Experimental Biology and Medicine 228 1282-1290.

Marshall GR \& Plant TM 1996 Puberty occurring either spontaneously or induced precociously in rhesus monkey (Macaca mulatta) is associated with a marked proliferation of Sertoli cells. Biology of Reproduction $\mathbf{5 4}$ 1192-1999. (doi:10.1095/biolreprod54.6.1192)

Marshall GR, Ramaswamy S \& Plant TM 2005 Gonadotropin independent proliferation of the pale type A spermatogonia in the adult rhesus monkey (Macaca mulatta). Biology of Reproduction 73 222-229. (doi:10.1095/biolreprod.104.038968)

Nistal M, Abaurrea MA \& Paniagua R 1982 Morphological and histometric study on the human Sertoli cell from birth to onset of puberty. Journal of Anatomy 134 351-363.

Paniagua R \& Nistal M 1984 Morphological and histological study of human spermatogonia from birth to the onset of puberty. Journal of Anatomy 139 535-552.

Plant TM 1985 A study of the role of the postnatal testes in determining the ontogeny of gonadotropin secretion in the male rhesus monkey (Macaca mulatta). Endocrinology 116 1341-1350. (doi:10.1210/endo-116-41341)

Plant TM 2010 Undifferentiated primate spermatogonia and their endocrine control. Trends in Endocrinology and Metabolism 21 488-495. (doi:10. 1016/j.tem.2010.03.001) 
Plant TM \& Witchel SF 2006 Puberty in non-human primates and humans. In Knobil and Neill's Physiology of Reproduction, pp. 2177-2230. Eds JRG Challis, DM de Kretser, JD Neill, DW Pfaff, TM Plant, JS Richards\& PM Wasserman. San Diego, USA: Elsevier.

Plant TM, Ramaswamy S, Simorangkir DR \& Marshall GR 2005 Postnatal and pubertal development of the rhesus monkey (Macaca mulatta) testis. Annals of the New York Academy of Sciences 1061 149-162. (doi:10. 1196/annals.1336.016)

Ramaswamy S 2005 Pubertal augmentation in juvenile rhesus monkey testosterone production induced by invariant gonadotropin stimulation is inhibited by estrogen. Journal of Clinical Endocrinology and Metabolism 90 5866-5875. (doi:10.1210/jc.2005-0092)

Ramaswamy S, Plant TM \& Marshall GR 2000 Pulsatile stimulation with recombinant single chain human luteinizing hormone elicits precocious Sertoli cell proliferation in the juvenile male rhesus monkey (Macaca mulatta). Biology of Reproduction 63 82-88. (doi:10.1095/biolreprod63. 1.82)

Ramaswamy S, Guerriero KA, Gibbs RB \& Plant TM 2008 Structural interactions between kisspeptin and $\mathrm{GnRH}$ neurons in the mediobasal hypothalamus of the male rhesus monkey (Macaca mulatta) as revealed by double immunofluorescence and confocal microscopy. Endocrinology 149 4387-4395. (doi:10.1210/en.2008-0438)

Ramaswamy S, Seminara SB, Ali B, Ciofi P, Amin NA \& Plant TM 2010 Neurokinin B stimulates $\mathrm{GnRH}$ release in the male monkey (Macaca mulatta) and is colocalized with kisspeptin in the arcuate nucleus. Endocrinology 151 4494-4503. (doi:10.1210/en.2010-0223)

de Rooij DG \& Russell LD 2000 All you wanted to know about spermatogonia but were afraid to ask. Journal of Andrology 21 776-798.

Sharpe RM 1994 Regulation of spermatogenesis. In The Physiology of Reproduction, pp. 1363-1434. Eds E Knobil\& JD Neill. New York: Raven Press.
Sharpe RM, McKinnell C, Kivlin C \& Fisher JS 2003 Proliferation and functional maturation of Sertoli cells, and their relevance to disorders of testis function in adulthood. Reproduction 125 769-784. (doi:10.1530/ rep.0.1250769)

Simorangkir DR, Marshall GR \& Plant TM 2003 Sertoli cell proliferation during prepubertal development in the rhesus monkey (Macaca mulatta) is maximal during infancy when gonadotropin secretion is robust. Journal of Clinical Endocrinology and Metabolism 88 4984-4989. (doi:10.1210/jc.2002-021858)

Simorangkir DR, Marshall GR, Ehmcke J, Schlatt S \& Plant TM 2005 Prepubertal expansion of dark and pale type A spermatogonia in the rhesus monkey (Macaca mulatta) results from proliferation during infantile and juvenile development in a gonadotropin independent manner. Biology of Reproduction 73 1109-1115. (doi:10.1095/biolreprod.105.044404)

Simorangkir DR, Marshall GR \& Plant TM 2009 A re-examination of proliferation and differentiation of type A spermatogonia in the adult rhesus monkey (Macaca mulatta). Human Reproduction 4 1596-1604. (doi:10.1093/humrep/dep051)

Whitfield ML, George LK, Grant GD \& Perou CM 2006 Common markers of proliferation. Nature Reviews. Cancer 6 99-106. (doi:10.1038/ nrc1802)

Zar JH 1974 Biostatistical analysis. pp. 185-186. Englewood Cliffs, NJ, USA: Prentice-Hall, Inc.

Received 31 October 2011

Revised manuscript received 16 December 2011

Accepted 9 January 2012 